\title{
DURKHEIM, VYGOTSKY E O CURRÍCULO DO FUTURO
}

\author{
MICHAEL F. D. YOUNG \\ Professor Emérito do Instituto de Educação da Universidade de Londres \\ tedpmmy@mentor.ioe.ac.uk
}

Tradução: Maria Lúcia Mendes Gomes, Regina Thompson e Vera Luiza Visackis Macedo*

\section{RESUMO}

Este artigo reporta-se às bases epistemológicas do currículo do futuro. Inicia examinando os debates em curso sobre o impacto das mudanças curriculares na economia global. A parte principal do texto refere-se à explicação e comparação de duas teorias sociais do conhecimento -a de Emile Durkheim e a do psicólogo russo Lev Vygotsky, focalizando particularmente a questão das origens do conhecimento e a relação entre o conhecimento cotidiano e o conhecimento teórico. O autor argumenta que a abordagem genético-histórica adotada por Vygotsky precisa ser combinada com a ênfase durkheimiana na realidade social do conhecimento. Finalmente, conclui com algumas observações acerca das implicações da comparação para a teoria de currículo contemporânea.

CURRICULLOCONHECIMENTOSADQUIRIDOS-DESENOLUMENTOCOGNITNO

\section{ABSTRACT}

DURKHEIM, VIGOTSKY AND THE CURRICULUM. This article is concerned with the epistemological basics of the curriculum of the future. It begins by examining current debates on the impact on the curriculum of changes in the global economy. The major part of the paper is concerned with an explication and comparison of two social theories of knowledge - those of Emile Durkheim and the Russian psychologist Lev Vygotsky, with a particular focus on the concern with the origins of knowledge and the relationship between everyday and theoretical knowledge. It argues that the genetichistorical approach adopted by Vygotsky needs to be combined with Durkheim's focus on the social reality of knowledge itself. It condudes with some observations on the implications of the comparison for contemporary curriculum theory.

CURRICULUM-EDUCATIONAL BACKGROUND-COGNITMEDEVELOPMENT

Este artigo é uma versão revisada de trabalho apresentado no $5^{\circ}$ Congresso da International Society for Cultural Research and Activity Theory, em Amsterdã, Vrije Universiteit, de 18 a 22 de junho de 2002.

* As tradutoras deste artigo são membros da Cooperativa de Profissionais em Tradução - Unitrad (unitrad@unitrad.com.br). 
Que princípios devem servir de base para o currículo do futuro? A primeira pergunta que me vem à mente é: o currículo continuará a se basear em uma nítida separação entre o conhecimento a ser adquirido na escola e o conhecimento que as pessoas adquirem em sua vida cotidiana? E, em segundo lugar, continuará a ter o caráter disciplinar estabelecido durante o século XIX ou será dada maior ênfase às habilidades práticas e sociais e ao tipo de conhecimento de que os adultos mais provavelmente precisam em uma economia global competitiva? As respostas a essas perguntas dependem, ao menos em parte, das suposições sobre a natureza do conhecimento e de como se presume que o conhecimento no qual o currículo se baseia seja diferente do conhecimento cotidiano das comunidades e locais de trabalho.

A crença de que, do ponto de vista cognitivo, o conhecimento adquirido por meio do currículo seja superior ao conhecimento adquirido na vida cotidiana constituiu a principal fundamentação para a ampliação da educação formal no século passado e para a reforma dos programas vocacionais que, anteriormente, baseavam-se somente no aprendizado adquirido no local de trabalho. Contudo, na década passada, as críticas ao currículo tradicional passaram a exercer influência cada vez maior. Uma crescente tensão aflorou entre: I) a fluidez e a abertura para as inovações das economias avançadas e bem-sucedidas - aquilo que alguns denominam "capitalismo rápido" - e a permanência de divisões relativamente rígidas entre as diferentes matérias e disciplinas escolares, e 2) entre o conhecimento adquirido por meio do currículo em geral e o conhecimento que as pessoas utilizam no trabatho e, de maneira mais geral, em suas vidas adultas. Por um lado, parece inconcebível que o currículo tenha podido permanecer imune às mudanças na sociedade e àquilo que alguns vêem como mudanças nos modos e lugares de produção do conhecimento (Gibbons et al., 1994). Por outro lado, o currículo disciplinar, isolado do conhecimento cotidiano, é uma característica quase universal dos sistemas educacionais e constituiu a base para a expansão maciça do conhecimento e crescimento econômico dos últimos I 50 anos.

Muller (2000) aguça ainda mais o dilema com que se defrontam os elaboradores do currículo, ao caracterizar essa tensão entre o currículo do "passado" e um possível currículo "do futuro", comparando os princípios de "insularidade" e "hibridismo". O princípio da insularidade enfatiza as diferenças existentes entre os tipos de conhecimento, e não a sua continuidade. Rejeita a hipótese de que as divisões e as classificações entre os tipos de conhecimento sejam somente reflexo das tradições herdadas do passado e pouco mais que uma justificativa dos interesses profissionais e das relações de poder existentes. Alega que essas classificações têm fundamentação tanto epistemológica quanto pedagógica; em outras palavras, relacio- 
nam-se de forma fundamental ao modo como as pessoas aprendem e como produzem novos conhecimentos. Portanto, a produção e a aquisição contínuas de novos conhecimentos impõem limites para as possibilidades de inovação no currículo, em particular no que diz respeito a transpor as fronteiras das disciplinas e matérias, para integrar o conhecimento teórico com know-how e habilidades práticas. Não é de surpreender, portanto, que o princípio da insularidade possa ser invocado para servir de alicerce para dar sustentação às doutrinas profundamente conservadoras, em defesa do status quo do currículo. No entanto, o argumento em defesa da insularidade não é somente político. Baseia-se na visão de que o conhecimento vai além da história e da sociedade. Como Descartes colocou há quase quatro séculos: o conhecimento real vai além de "todos os costumes e exemplos".

O princípio do hibridismo, por outro lado, rejeita qualquer argumento de que as fronteiras e classificações do currículo sejam reflexo do próprio conhecimento e de que sejam algo mais que um produto da história. $O$ hibridismo enfatiza a "unidade e a continuidade essenciais das formas e tipos de conhecimento... (e) a permeabilidade das fronteiras classificatórias" (Muller, 2000, grifo meu). A defesa do hibridismo não é feita sobre fundamentos pedagógicos ou epistemológicos', mas sim em termos de sua coerência com a natureza "sem fronteiras" que cada vez mais caracteriza as economias modernas (Reich, 1991). Essa visão "socioconstrutivista" do conhecimento sempre apelou para os princípios fundamentais como base para expor interesses específicos associados às fronteiras existentes e suas reivindicações à universalidade. São esses os argumentos apresentados pelos seguidores pós-modernistas de Nietszche, que alegam ser o hibridismo uma idéia nova apenas na aparência; para eles, os critérios epistemológicos, assim como os pedagógicos, nunca passaram de uma forma de mascarar as questões de poder e interesse.

Existem, no entanto, razões práticas para que um currículo alicerçado no princípio do hibridismo tenha começado a despertar o interesse dos elaboradores de políticas educacionais, uma vez que ele parece convergir para os novos objetivos da política de inclusão e responsabilidade sociais. Ao mesmo tempo em que as pressões por inclusão social exigem que o currículo vá "além de suas fronteiras" e reconheça o conhecimento e a experiência daqueles tradicionalmente excluídos da educação formal, as pressões por uma obrigatoriedade maior de prestar contas colocam em questão a autonomia dos produtores de conhecimento especializado.

I Na verdade, aqueles que rejeitam o hibridismo tendem a rejeitar a possibilidade de fundamentos pedagógicos. 
Em ambos os casos, os argumentos sociais e econômicos em prol de um currículo "sensível", que possa servir de base para novos tipos de habilidades e conhecimentos que transcendam as fronteiras disciplinares e as divisões acadêmicas/vocacionais atuais, opõem-se à insularidade do currículo acadêmico tradicional. Ao rejeitar qualquer vínculo entre as classificações do conhecimento específico e os requisitos pedagógicos ou princípios epistemológicos, o princípio do hibridismo justifica a crença de que as decisões sobre o currículo dependem, em última análise, das pressões do mercado e das prioridades políticas.

Este artigo pretende encontrar uma base para o currículo que evite tanto o conservadorismo aistórico da disciplinaridade tradicional, quanto as conseqüências incertas do hibridismo e sua renúncia a quaisquer critérios pedagógicos ou epistemológicos. Para isso, analisaremos e compararemos alguns aspectos das teorias sociais e educacionais do sociólogo francês Émile Durkheim e do psicólogo russo Lev Vygotsky. Ambos, embora de maneiras diversas, deram prioridade à diferenciação do conhecimento, principalmente às diferenças entre o conhecimento teórico e o conhecimento da vida cotidiana, em lugar de sua unidade. Da mesma forma, os dois teóricos tentaram situar a diferenciação do conhecimento dentro dos limites de suas teorias sociais.

A seção I descreve a base teórica da idéia de insularidade nos escritos de Émile Durkheim ( 1961) e, em especial, as diferenças que ele faz entre as ordens de significado de sagrado e profano. A seção 2 compara as teorias sociais de Durkheim e Vygotsky sobre conhecimento e como eles, de diferentes formas, recorreram às etnografias de sociedades primitivas. A seção 3 examina as semelhanças entre a distinção do conhecimento científico/cotidiano em Vygotsky e a distinção do sagrado e profano em Durkheim. A seção 4 interpreta a distinção de Vygotsky, de uma ótica dialética, em termos de sua teoria geral do desenvolvimento humano.

Esse tipo de abordagem pode oferecer uma forma de se ir além de Durkheim, ao situar o conhecimento e o currículo dentro de uma teoria mais ampla de mudança social. No entanto, permito-me sugerir que, embora Vygotsky evite o aistoricismo de Durkheim, a abordagem dialética introduz novos problemas que ela própria é incapaz de resolver. Ao situar o conhecimento na história das ações humanas no mundo externo, o conhecimento, como categoria distinta que se refere a causas e explicações não conectadas a objetivos específicos, desaparece². Com-

2 Existem indicações de que Vygotsky tinha consciência da necessidade de lidar-se especificamente com o problema do conhecimento, embora não fique claro como ele o abordaria se tivesse vivido o suficiente para isso. 
preensivelmente, a grande maioria dos teóricos soviéticos da época de Vygotsky alegava que a teoria marxista sobre o papel histórico desempenhado pela classe trabalhadora havia solucionado o problema do conhecimento. Os sucessores de Vygotsky no Ocidente tentaram evitar esse dogmatismo marxista, assim como as implicações relativistas de uma abordagem dialética, preservando a universalidade do princípio da contradição, embora generalizando-o das relações de classe social para a vida social em geral. Essa abordagem encontra paralelos em Dewey, que também advogava uma versão não dogmática de um método dialético, mas que dependia de sua crença na ciência e na democratização progressiva da sociedade norte-americana como critérios de conhecimento e verdade (Rytina, Loomis, 1970). Minha conclusão é que, em si própria, uma abordagem dialética do conhecimento é inadequada para servir de base para um currículo do futuro, e sugiro que seja necessário combinar uma visão histórica do conhecimento com aquilo que denomino conceito realista social de sua objetividade.

$\mathrm{Na}$ tentativa de lidar com os problemas não solucionados de uma abordagem dialética, na seção 5 abordo rapidamente a análise de Durkheim sobre pragmatismo (Durkheim, 1983). Defendo a idéia de que um conceito sobre o conhecimento que mantenha uma relativa independência dos contextos em que foi produzido, adquirido e desenvolvido na história, é necessário tanto para servir de base ao currículo, quanto para justificar a expansão sem precedentes do conhecimento a partir do século XVII.

Em segundo lugar, tento demonstrar que o conhecimento como categoria não é aistórico; ele emergiu como produto dos códigos, regras e práticas das pessoas envolvidas em áreas especializadas de pesquisa e dos debates sobre conhecimento que se desenvolveram nessas áreas (Collins, 1998). O artigo encerra-se na seção 7, com algumas observações sobre as questões a respeito do currículo com as quais iniciei o texto.

\section{DURKHEIM, CONHECIMENTO E CURRÍCULO}

Durkheim não desenvolveu a abordagem sobre conhecimento como parte explícita de sua teoria educacional e foi só relativamente há pouco tempo, graças fundamentalmente ao trabalho de Basil Bernstein ${ }^{3}$, que se reconheceu sua impor-

3 Interpretar e desenvolver as idéias de Durkheim foi tema do trabalho relativamente precoce de Bernstein (197I) e de seu último livro, que incluiu o importante artigo sobre as estruturas verticais e horizontais do conhecimento (Bernstein, 2000). 
tância para os debates sobre o currículo. Durkheim tinha dois objetivos ao desenvolver uma sociologia do conhecimento. Primeiramente, isso fazia parte de uma preocupação maior em estabelecer um papel diferenciado para a sociologia como ciência de aplicabilidade universal. Em segundo lugar, ele desejava estabelecer uma base sólida (e, portanto, para ele, necessariamente sociológica) de ciência e verdade que superasse aquilo que, a seu ver, constituía o principal ponto fraco da filosofia de sua época e de como ela era dominada pelo racionalismo e empirismo (Ward, 1996). Existem no mínimo duas possíveis razões por que os teóricos do currículo negligenciaram a sociologia do conhecimento de Durkheim. Uma pode ter sido o fato de seu enfoque não abordar áreas específicas do conhecimento, tais como as ciências naturais ou sociais, mas sim procurar fornecer uma teoria sociológica do conhecimento em geral. Em segundo lugar, pelo fato de sua teoria social do conhecimento não se basear, como foi o caso com seu estudo sobre o suicídio, em dados contemporâneos, mas sim em estudos etnográficos sobre a religião em sociedades que não tinham instituições de educação formal.

O ponto de partida de Durkheim era a realidade social da religião, que ele via como exemplo daquilo que denominava "representações coletivas". Para Durkheim, as representações coletivas originam-se nas comunidades e incluem as categorias mais básicas do pensamento humano, tais como causalidade, tempo e espaço. Além disso, Durkheim argumentava que essas representações coletivas, embora inicialmente de conteúdo religioso, constituíam o paradigma de todas as formas avançadas do conhecimento teórico. Em seu relato sobre religião e a emergência das representações coletivas, era fundamental a separação que Durkheim fazia entre as ordens de significado de profano e sagrado, que ele afirmava ser característica inequívoca de todas as sociedades primitivas que estudara4. "Em toda a história do pensamento humano, não existe outro exemplo de duas categorias de coisas tão profundamente diferenciadas ou tão radicalmente opostas uma da outra" (Durkheim, |961, p.53).

Para Durkheim, o profano dizia respeito a como as pessoas reagem a seu mundo cotidiano - de formas práticas, imediatas e particulares. Ele distinguia esse mundo cotidiano profano do mundo sagrado da religião, que via como inventado, arbitrário (no sentido de não estar ligado a objetos e eventos específicos) e, fundamentalmente, coletivo. $\bigcirc$ sagrado consistia em sistemas de conceitos correlatos,

4 O antropólogo social Robin Horton (1974) afirma que Durkheim era, de certa forma, ambivalente no que se refere a até que ponto a distinção sagrado/profano sobreviveu nas sociedades modernas de sua época. 
porém inobserváveis. Pelo fato de não estarem ligados a observações ou experiências específicas, esses sistemas de conceitos tinham, para Durkheim, uma objetividade proveniente de seu caráter compartilhado, social, e pelo fato de serem externos à percepção dos indivíduos. Pelo fato de esses conceitos não terem origem individual, o sagrado era relativamente fixo. Além disso, em sua condição de externo aos indivíduos, o sagrado exibia, na forma porém não no conteúdo, uma característica distinta de conhecimento e verdade - os indivíduos sentiam-se pressionados a aceitá-lo.

A religião era importante para Durkheim como exemplo de representações coletivas compartilhadas, não como prova da existência de Deus. Ele via a religião como portadora de uma função integradora ${ }^{5}$, capaz de manter a solidariedade social, e que servia de modelo para todos os outros tipos de pensamento abstrato, inclusive a ciência moderna que consiste em conceitos inobserváveis. Em outras palavras, os totens dos aborígenes e as leis sobre gases do físico eram, ao menos na forma, idênticos para Durkheim. Ele identificava duas características principais, que conferiam ao sagrado seu status de paradigma como base do conhecimento futuro. Primeiro, na medida em que era constituído de um conjunto de conceitos compartilhados por uma comunidade, embora não conectado a objetos ou eventos específicos, o sagrado permitia que as pessoas fizessem conexões entre objetos e eventos que, com base em sua experiência cotidiana, não pareciam se correlacionar. Essa capacidade de conexão é fundamental para os cientistas e o homem moderno em geral, porém não o era menos para os membros das comunidades primitivas que vivenciavam a maior parte dos eventos naturais como forças externas sobre as quais tinham pouco controle. Em segundo lugar, por não estar conectado ao mundo do cotidiano, o sagrado permite que as pessoas projetem para além do presente, para um futuro. Nas sociedades primitivas a projeção referia-se à capacidade de as pessoas intuírem algum tipo de vida além do seu mundo cotidiano, ao passo que nas sociedades modernas essa projeção transforma-se no potencial de predizer com base nos conceitos científicos e, de forma mais geral, de ser capaz de conceber alternativas.

Para Durkheim, essas duas características distinguiam o conhecimento teórico (no sentido de conhecimento constituído por um sistema de conceitos), seja religioso ou científico, do conhecimento cotidiano. Ao mesmo tempo, a distinção não se referia a julgar se um tipo de conhecimento era superior ao outro, a ênfase

5 Durkheim não se preocupava com as relações intersociais das quais a religião, até mesmo em sua época, estava longe de ter essa função integradora. 
repousava sobre suas diferenças. Como Durkheim apontava, a vida cotidiana não seria possível se só pudéssemos contar com o conhecimento teórico. De forma semelhante, se nosso pensamento fosse restrito ao profano ou ao cotidiano, somente de formas muito limitadas seria possível extrair sentido do mundo. Além disso, o pensamento cotidiano, situado como está em respostas a contextos espeć́ficos, não serve de base para desenvolver um conhecimento objetivo do mundo que transcenda esses contextos. $\bigcirc$ argumento de Durkheim era de que todas as sociedades se caracterizam por um nível de especialização entre esses dois tipos de conhecimento. $\bigcirc$ que distingue as sociedades não é a especialização em si ou o fato de dispor de conceitos abstratos inobserváveis, mas sim o alcance da especialização, a natureza dos conceitos ${ }^{6}$ e até que ponto os conceitos são sujeitos a críticas e submetidos a testes empíricos.

Gellner (1992) alega que a importância da sociologia do conhecimento de Durkheim diz respeito ao fato de ela ser um argumento poderoso para as origens sociais (em oposição às individuais) do pensamento abstrato; por esta razão, Durkheim rompeu com o individualismo de Descartes e com aquilo que via como o idealismo abstrato de Hegel. O pensamento abstrato ou teórico não é, para Durkheim, uma característica ou capacidade de indivíduos particulares, mas sim uma característica das sociedades - de todas as sociedades ${ }^{7}$. Ao demonstrar como as características do pensamento abstrato, principalmente seu escopo e sua natureza sistemática, relacionam-se com suas origens em atividades sociais, a sociologia do conhecimento de Durkheim é sincrônica, vê o conhecimento como representações coletivas desenvolvidas quando as pessoas formam sociedades. Essa teoria revela-se menos adequada quando se trata de fornecer um relato diacrônico da diferenciação e expansão do conhecimento nas sociedades modernas e sua associação com métodos empíricos e formas especializadas de análise crítica.

Um outro problema com a exposição de Durkheim é a pouca atenção que ele dá à estratificação interna do conhecimento no seio das sociedades ${ }^{8}$. Parece

6 Por exemplo, se os conceitos podem ou não ser representados matematicamente (Collins, 1998).

7 Logo, com base em um argumento de Durkheim, a capacidade para o pensamento abstrato não era uma capacidade individual distribuída uniformemente, mas uma propriedade decorrente do fato de ser membro de uma sociedade.

8 Se utilizarmos os termos que Durkheim usava para analisar a divisão social do trabalho, esta estratificação do conhecimento seria um exemplo daquilo a que ele se referia como a divisão "forçada" do trabalho (Durkheim, 1964). 
provável que essa negligência se deva parcialmente ao fato de a sociologia do conhecimento de Durkheim ter-se baseado em estudos de sociedades de pequena escala, com pouca estratificação. Uma extrapolação dos estudos sobre sociedades primitivas esbarraria no fato de a sociologia do conhecimento de Durkheim evitar o ponto em que as relações de poder moldam as relações entre os tipos de conhecimento, convertendo-os em hierarquias (Young, 1998). Além disso, sua ênfase nas diferenças entre os tipos de conhecimento nas sociedades que ele estudou negligencia a tendência, nas sociedades modernas, de o conhecimento profano de algumas reivindicar o status de sagrado. É essa negligência do elo entre poder e conhecimento que alguns críticos radicais e pós-modernistas de Durkheim enfatizaram. Porém, em suas críticas, eles próprios tendem a reduzir as análises do conhecimento a questões de poder e a negligenciar as próprias questões sobre conhecimento com que Durkheim se preocupava (Moore, Young, 200I).

Um outro problema com a teoria social do conhecimento de Durkheim é que, ao mesmo tempo em que nela está implícita uma visão evolucionária do desenvolvimento do conhecimento, ele pouco fala sobre o processo. Sua teoria é convincente no que diz respeito à distinção entre teoria e senso comum e suas origens na separação das ordens de significado de sagrado e profano; contudo, Durkheim não esclarece como um tipo de conceito inobservável (por exemplo, a força como uma idéia ou totem místico) transforma-se em outro (a força como idéia científica - como a gravidade). Como a grande maioria dos intelectuais de sua época, Durkheim via a ciência como pressuposto para seu modelo de conhecimento e não fazia distinção entre os dois. $\bigcirc$ que continua sendo importante na sua visão de conhecimento e ciência é a ênfase na base conceitual, em lugar da base empírica, e a demonstração de que essa base conceitual tem origens sociais.

Na busca por uma abordagem mais histórica e dinâmica do conhecimento que possa levar em consideração o impacto da mudança social sobre a base do conhecimento do currículo, compararei a abordagem de Durkheim com as idéias do psicólogo e teórico social russo Lev Vygotsky. A diferença entre o pensamento científico (ou teórico) e o do senso comum ocupava, como em Durkheim, o centro da teoria social e educacional de Vygotsky. No entanto, as diferenças, assim como as semelhanças entre os dois conjuntos de idéias, são importantes e, principalmente, a maneira pela qual essas diferenças se ligam à forma pela qual cada teórico interpretava as origens sociais do conhecimento e da ciência. 


\section{ORIGENS SOCIAIS DO CONHECIMENTO EM VYGOTSKY E DURKHEIM}

A diferença entre conceitos científicos e cotidianos era parte integrante da teoria do desenvolvimento humano de Vygotsky e tinha semelhanças significativas com a distinção entre sagrado e profano de Durkheim?. No entanto, embora Vygotsky estivesse sem dúvida familiarizado com o trabalho de Durkheim ${ }^{10}$, encontrei poucas referências explícitas a Durkheim em seus escritos traduzidos para o inglês ". O tópico principal sobre conceitos científicos e cotidianos, em Collected Works, faz muitas referências à distinção entre conceitos espontâneos e científicos, mas não se refere explicitamente a Durkheim ${ }^{12}$.

Vygotsky mantinha sempre um enfoque no desenvolvimento humano. Queria demonstrar que: "não foram somente as relações entre o homem e a natureza que mudaram. O próprio homem mudou e evoluiu. A natureza humana mudou no curso da história" (Luria, Vygotsky, 1992, p.41, grifo meu).

Era essa preocupação de evitar uma visão essencialista e aistórica da natureza humana que levou Vygotsky a se interessar pelo desenvolvimento histórico da psique humana e a razão por que se voltou para estudos dos povos chamados "primitivos" e, em particular, para o trabalho de Levy-Bruhl. Vygotsky retirou duas importantes lições de Levy-Bruhl - sua proposição de uma teoria não individualista de pensamento e sua hipótese de que "diferentes tipos de sociedade são associadas com diferentes tipos de psicologia humana” (p.44). Vygotsky chama a atenção para o fato de que para Levy Bruhl,"as funções psíquicas superiores no homem primitivo são profundamente diferentes das mesmas funções no homem civilizado... o próprio tipo de raciocínio... (é)... uma variável histórica" (Luria, Vygotsky, 1992, p.44).

Vygotsky observou também que Levy Bruhl negligenciava o lado prático (ou, em termos marxistas, o lado produtivo) das sociedades primitivas. Diferentemente de Levy-Bruhl, a visão de Vygotsky era de que mesmo o homem primitivo era

9 Como Daniels (2000) aponta, existem semelhanças também com as estruturas verticais e horizontais de conhecimento de Bernstein.

10 Durkheim morreu em 1918, pouco antes de Vygotsky iniciar sua carreira.

I I Um exemplo disso é quando Vygotsky afirma que "do ponto de vista filosófico, este argumento (de que o pensamento lógico e a necessidade do conhecimento da própria verdade surgem na interação da consciência da criança e da consciência de outros) é reminescente de Durkheim" (Vygotsky, 1988, p.85).

12 Esta pode ter sido uma decisão política tática, uma vez que muitos escritores soviéticos da época viam qualquer referência a Durkheim como um sinal de revisionismo burguês. 
capaz de: "pensamento lógico objetivo, sempre que o objetivo de suas ações fosse uma adaptação direta da natureza" (Luria, Vygotsky, 1992, p.45, grifo meu).

Vygotsky não rejeitava a distinção que Levy-Bruhl fazia entre o pensamento primitivo e o moderno, que ele via como base para a idéia de que o pensamento humano varia entre as sociedades e se desenvolve com o passar do tempo. Contudo, parece ter identificado o potencial de desenvolvimento do pensamento primitivo com aquelas "ações em adaptação direta da natureza", a que o próprio LevyBruhl dava pouca atenção.

Vygotsky não parece, ao menos explicitamente, estar familiarizado com a análise significativamente diferente de Durkheim sobre a mentalidade primitiva. Segundo Horton (1974), "Levy Bruhl vê o pensamento 'primitivo' e o pensamento 'moderno' como opostos... ao passo que Durkheim... vê 'primitivo' e 'moderno' como dois estágios de um único processo evolucionário...".

Temos, portanto, três abordagens diferentes sobre as origens sociais do conhecimento. Levy Bruhl considerava o pensamento do homem primitivo como caracterizado por uma combinação de misticismo e senso comum. Para ele, no processo da civilização, as sociedades foram gradualmente prescindindo do misticismo e substituindo-o pelos métodos empíricos da ciência. Embora Vygotsky concordasse com Levy Bruhl em que o pensamento primitivo consistia em uma combinação do prático e do místico, ele deu muito maior ênfase ao aspecto prático, principalmente "a invenção de ferramentas, a caça, a criação de animais, a agricultura e a luta, todos [os quais] exigem dele um pensamento lógico que seja rea/e não somente aparente" (Luria, Vygotsky, 1992, p.45).

Dessa forma, Vygotsky situava no trabalho humano tanto as origens quanto o desenvolvimento da psique do homem. Para Vygotsky, o desenvolvimento do conhecimento surgiu a partir do trabalho humano, como parte do desenvolvimento humano em geral. Vygotsky não parecia abordar exatamente como as formas científicas do pensamento desenvolveram-se a partir dos primórdios da luta pela sobrevivência humana.

Durkheim, por outro lado, interpretava os achados das etnografias das sociedades primitivas de maneira muito diferente de Levy Bruhl e de Vygotsky. Primeiramente, como aponta Horton ( 1974), ele chamava a atenção para: a) a continuidade entre as classificações religiosas primitivas e as classificações das ciências e b) a diferença entre as classificações técnico-práticas e científicas nas sociedades modernas. Embora ele não o diga de forma explícita, é de se supor que Vygotsky tenha rejeitado cada uma dessas proposições. Ele teria concordado com Levy Bruhl em que a ciência não é uma continuidade da religião, mas sim sua antítese. Além disso, teria 
rejeitado a distinção que Durkheim faz entre o técnico e o científico. Em segundo lugar, Durkheim diferia de Levy Bruhl em sua caracterização do pensamento primitivo; para ele, não se tratava apenas de constatar que o pensamento primitivo consistia no pensamento prático do senso comum e do pensamento místico, mas sim que o senso comum (o profano) e o pensamento místico ou conceitual (o sagrado) eram separados e diferentes. Era o caráter compartilhado e, conseqüentemente, social do pensamento místico (o sagrado, para usar os termos de Durkheim) e sua separação da vida cotidiana, e não seu conteúdo, que lhe conferiam objetividade e permitiam que se tornasse a base da ciência.

Ao contrário de Durkheim, era na atividade prática do homem primitivo que Vygotsky via o germe do conhecimento, que posteriormente evoluiu para conceitos científicos. Para Durkheim, em contrapartida, o germe da ciência moderna deve ser encontrado não nas atividades práticas do homem, mas na objetividade, baseada no social, da religião das sociedades primitivas. Essas diferenças entre Durkheim e Vygotsky repousam no centro de suas abordagens distintas sobre o conhecimento. Para o primeiro, a objetividade do conhecimento é conceitual e se situa na sociedade, originalmente na religião. Para o segundo, a objetividade do conhecimento também se situa no social, porém nas atividades produtivas do homem na história. Retomarei este ponto mais adiante. A próxima seção aborda uma comparação mais específica das diferenças entre Durkheim e Vygotsky.

\section{CONHECIMENTO CIENTÍFICO E COTIDIANO: COMPARAÇÃO ENTRE AS ABORDAGENS DE VYGOTSKY E DURKHEIM}

Vygotsky identifica uma série de características que diferenciam os conceitos científicos e cotidianos. Cada uma delas pode ser comparada com a distinção que Durkheim faz entre o sagrado e o profano.

a. Essas características dizem respeito a diferentes relações com os objetos. Para Vygotsky, enquanto a relação de uma criança com o mundo por meio de seus conceitos cotidianos ocorre mediante aquilo que ela vê ou vivência diretamente, no caso dos conceitos científicos a relação é mediada por esses conceitos e não depende de experiência direta.

b. A ausência ou presença de um sistema (de relações entre conceitos) era, para $V y g o t s k y$, a diferença fundamental entre conceitos cotidianos e científicos. 
Ambas as características são expressas de formas quase idênticas por Durkheim, em sua análise sobre as diferenças existentes entre as ordens de significado de sagrado e profano.

c. Uma criança (poderia ser também um adulto, obviamente) utiliza conceitos cotidianos, sem ter consciência de que o faz, ao passo que a consciência reflexiva é (ou deveria ser) sempre uma característica do uso de conceitos científicos. Vygotsky traça um paralelo com a gramática, chamando a atenção para o fato de que qualquer pessoa pode usar a gramática para construir sentenças, mesmo desconhecendo as regras gramaticais ${ }^{13}$. Existe um problema neste ponto, uma vez que a definição parece se referir ao uso, assim como ao conteúdo. Um conceito qualquer é considerado científico quando é usado reflexivamente oualguns conceitos são científicos mesmo quando não são usados reflexivamente? Em Durkheim, não encontramos a mesma preocupação explícita sobre reflexibilidade e consciência, embora ao escrever sobre o sagrado como a base de uma "faculdade de idealizar... substituindo o mundo real por um outro diferente, para o qual (as pessoas conseguem) se transportar por meio do pensamento... (por meio do qual) alguma coisa é acrescentada ao real e acima dele" (Durkheim, 1961, p.469).

Durkheim está, a meu ver, chegando a um ponto semelhante ao de Vygotsky, o qual também enfatiza o inter-relacionamento entre os dois tipos de conceitos nos seguintes termos: "Os rudimentos da sistematização penetram primeiro na mente da criança por meio de seu contato com conceitos científicos, para em seguida serem transferidos para conceitos cotidianos, alterando sua estrutura psicológica de cima para baixo" (Vygotsky, 1962, p.93).

Para Vygotsky, esse inter-relacionamento entre os dois tipos de conceitos é subjacente à inseparabilidade do aprendizado da instrução e é uma proposição crucial tanto para o currículo quanto para a pesquisa educacional. Ele argumenta que os dois tipos de conceitos desenvolvem-se em direções opostas: "o desenvolvimento de conceitos espontâneos em uma criança avança em sentido ascendente e o desenvolvimento de seus conceitos científicos, em sentido descendente" (I 962, p. I08).

13 Ao mesmo tempo, Vygotsky enfatiza explicitamente por que isto não constitui justificativa para não ensinar gramática (p. 100). 
Enquanto os conceitos cientíicos têm início com sua definição verbal e se desenvolvem "à medida que são complementados com trabalho escolar e leitura adicionais", os conceitos espontâneos já são em si mesmos "ricos em experiência", mas, devido ao fato de não fazerem parte de um sistema, não fornecem explicações e podem gerar confusões" (Vygotsky, 1962).

Como Vygotsky aponta, essas diferenças dizem respeito às diferentes formas pelas quais os dois tipos de conceitos emergem - em um caso, normalmente, por meio de encontros pessoais, em situações concretas e, no outro caso, em uma "atitude mediada voltada para o objeto". Ao considerar as relações entre os dois tipos de conceitos, deparamos com as principais diferenças entre Vygotsky e Durkheim. Para Vygotsky, as inter-relações entre os dois tipos eram cruciais - em um sentido, elas constituem o processo de aprendizado. Para Durkheim, que estava mais preocupado com a ordem social do que com o aprendizado, as diferenças entre os dois tipos é que eram cruciais. Fiz referência anterior a seu comentário de que "não existe outro exemplo de duas categorias de coisas tão profundamente distintas ou tão radicalmente opostas" (Durkheim, I96। , p.53). Ele continua dizendo: "Isto não equivale a dizer que um ser humano não consegue nunca passar de um desses mundos para o outro, mas a maneira como essa passagem é realizada... demonstra a dualidade essencial dos reinos" (p.54).

Ao contrário de Vygotsky, Durkheim não está basicamente preocupado com um processo; está enfatizando o poder (social) e a objetividade de classificações que, afirma, se aplicam tanto ao relacionamento entre ciência e senso comum de hoje quanto se aplicavam à separação dos mundos sagrado e profano nas sociedades primitivas.

Em seu livro recentemente publicado, Daniels (2000) chama a atenção para a análise de Vygotsky, que enfatiza tanto as diferenças entre conceitos cotidianos e cientíícos quanto sua interdependência. No entanto, embora reconheça seus vários aspectos positivos, a ênfase principal de Vygotsky repousa nas limitações dos conceitos cotidianos. Para ele, assim como o senso comum para Durkheim, os conceitos cotidianos não têm qualquer "capacidade de abstração e generalização" e deixam de fornecer ao aluno os recursos para que possa atuar de maneira voluntária. Embora nunca fique explícito o que entende por ciência, Vygotsky não restringe explicitamente seu significado às ciências naturais. Alguns críticos sugeriram que, como seus exemplos geralmente referem-se à teoria evolucionista de Darwin ou a Marx, ele deve ter dado preferência a uma interpretação marxista do termo ciência. A próxima seção, portanto, situa o conhecimento científico e cotidiano de Vygotsky mais amplamente na interpretação marxista do método dialético. 


\section{UMA INTERPRETAÇÃO DIALÉTICA DA DISTINÇÃO ENTRE CONCEITOS CIENTÍFICOS E COTIDIANOS}

Embora Vygotsky escreva especificamente sobre metodologia, uma indicação de que ele estava pensando em termos dialéticos está presente em sua referência a

O salto dialético... (como)... não apenas uma transição de matéria incapaz de provocar sensação para matéria capaz de provocar sensação, mas uma transição da sensação para o pensamento. Isso implica que a realidade é refletida na consciência de um modo qualitativamente diferente no pensamento do que éna sensação imediata". (p.47, 1988, grifos meus)

Sua distinção entre pensamento e sensação é em si uma indicação das diferenças que ressaltou entre a ciência e o senso comum. Meu interesse é explorar o quanto uma interpretação dialética da distinção feita por Vygotsky pode nos ajudar a superar os problemas da abordagem aistórica de Durkheim sobre o conhecimento.

Desde Hegel, teorias sociais como o marxismo e o pragmatismo procuraram abordar o problema do conhecimento como sendo algo objetivo e inserido na história, vinculando o conhecimento aos propósitos humanos ao invés de tratá-lo por si próprio e independente da história. Entretanto, na tentativa de evitar conferir ao conhecimento uma autonomia espúria, essas teorias, até onde consigo ver, resultam em relativismo ou dogmatismo. Na ausência de um conceito de conhecimento ou verdade que seja de alguma maneira independente dos "esforços socialmente enraizados dos agentes históricos”, os julgamentos são inevitavelmente feitos na base dos critérios tratados como determinados e além da argumentação. $\mathrm{Na}$ dialética idealista de Hegel, os critérios do conhecimento e da verdade estavam vinculados ao movimento da Razão na história; no materialismo de Marx, estavam vinculados à luta de classes; e no pragmatismo, a um idealismo desmistificado que idolatrava uma visão prática e instrumental da ciência. Este não é o lugar para enumerar os problemas das abordagens dialéticas da verdade, exceto para afirmar que todas elas se reduzem muito facilmente ao instrumentalismo ou à justificativa de "o que é" em casos específicos. Hegel distingue-se dos outros, não apenas por ter sido menos específico que Marx ou que os pragmatistas quanto ao que a Razão realmente significava na história, mas também por que, às vezes, parecia ver o Estadonação emergente de seu tempo como a materialização da razão; no entanto, isso mostrou-se um critério tão problemático quanto os critérios mais tarde oferecidos por Marx e pelos pragmatistas. Entretanto, se não temos nenhum conceito inde- 
pendente de conhecimento, a lógica dialética nos deixa em uma posição relativista insustentável.

Pode ser que Vygotsky estivesse consciente de algumas das dificuldades apresentadas pelas abordagens dialéticas e que isso explique por que, embora intrigado por elas, toda a questão do método tenha permanecido inexplorada em seus escritos. Entrentanto, considerarei aqui a interpretação explicitamente dialética que Engestrom (|99|) faz da distinção entre os conceitos científicos e do senso comum, estabelecida por Vygotsky. A exposição de Engestrom deixa claro o que está envolvido ao se pensar sobre a distinção de Vygotsky na estrutura da lógica dialética e sugere por que, apesar de seu poder evocativo como crítica, o método dialético é incapaz de cumprir sua promessa de teoria capaz de gerar novos conhecimentos $^{14}$. Esta seção do artigo recorre de modo substancial à exposição de Engestrom.

A lógica dialética, seja aplicada ao conhecimento seja ao desenvolvimento humano, em geral depende, para sua objetividade, da sua alegação de conhecer o curso futuro da história. Engestrom começa mostrando que, ao contrário do que acontece com outras formas de lógica, a lógica dialética alega basear-se não em abstrações, mas no movimento real da história. É essa idéia de mudança histórica que oferece a promessa de solucionar o problema do significado dos conceitos "científicos" de Vygotsky. A dialética, afirma Engestrom, reverte a direção da lógica convencional

...ao invés de ver os fenômenos "concretos" como algo palpável pelos sentidos e a "abstração" como um processo conceitual ou mentalmente construído, "Concreto" ("as coisas como elas são") refere-se à interligação sistêmica das coisas. Em outras palavras, os fenômenos concretos são o resultado, não o ponto de partida do pensamento. (1991, grifos meus)

Da perspectiva do método dialético, abstrações formais, como aquelas desenvolvidas por Durkheim, podem apenas separar as características arbitrárias dos objetos de suas interconexões "reais". Em contraste, os conceitos científicos e coti-

I4 Existe, é claro, um paralelo com o marxismo como uma teoria da sociedade. Apesar da perda de interesse no marxismo, tanto entre os políticos de esquerda quanto na comunidade acadêmica desde a década de 1980, ele permanece uma crítica poderosa, ainda que cada vez mais negligenciada, do capitalismo contemporâneo. Por outro lado, poucos ainda afirmariam que ele oferece uma teoria adequada da transformação social ou uma base para gerar alternativas não capitalistas. 
dianos de Vygotsky, vistos de modo dialético, são abstrações concretas que refletem e reconstroem a natureza sistêmica e interligada dos objetos a que se referem.

Para ilustrar esse argumento, Engestrom refere-se à comparação de Marx e Engels entre seus conceitos de proletariado como "a classe mais revolucionária da sociedade burguesa - o coveiro do capitalismo" e a definição sociológica típica da classe trabalhadora como "a classe mais oprimida e dominada que sofre passivamente a pobreza, capaz de, no máximo, apenas uma rebelião desesperada provocada pela fome". Em outras palavras, afirma Engestrom, o conceito marxista de proletariado foi a expressão teórica das condições objetivas da classe trabalhadora. A verdade dessa proposição surge, segundo o filósofo russo llyenkov, "pela transformação real do proletariado de uma 'classe em si' para uma 'classe para si'” (apud Engestrom, 1991).

Temos, portanto, um exemplo da transformação materialista de Marx da dialética de Hegel ou de seu movimento da Razão na história. Infelizmente a história confirmou, se é que ela pode confirmar alguma coisa, o oposto do que afirmava llyenkov. Em uma reviravolta irônica, pode-se argumentar que, ao forçar o capitalismo a transformar-se, o proletariado acabou sendo seu próprio coveiro, e não do capitalismo.

Engestrom mais uma vez cita llyenkov, que afirma que um conceito dialético "expressa uma realidade que, embora sendo um fenômeno bastante particular... é ao mesmo tempo um elemento genuinamente universal... em todos os outros fenômenos particulares".

Segue-se que a tarefa da formação de um conceito genuíno é identificar esses "elementos universais genuínos". Engestrom então faz a pergunta-chave: "como tais conceitos (genuínos) surgem pela primeira vez?".

Para responder a essa pergunta, volta-se para outros três filósofos russos, Arsenev, Bibler e Kedrov, os quais argumentam que conceitos genuínos surgem da interação das forças envolvidas em qualquer atividade produtiva. Logo, os conceitos científicos não precisam ser limitados a esses desenvolvidos e utilizados na atividade historicamente formada chamada ciência. "Do nosso ponto de vista, qualquer... conceito é potencialmente... científico-teórico" (Arsenev, Bibler, Kedrov apud Engestrom, 1991, grifo meu).

Assim, o pensamento cotidiano tem em princípio o mesmo potencial teórico dos conceitos conscientemente elaborados da ciência. Engestrom cita llyenkov defendendo uma idéia similar, ao afirmar que "as leis universais do pensamento são as mesmas no pensamento científico e no chamado pensamento cotidiano" (llyenkov apud Engestrom, |99|). 
A distinção entre os conceitos científicos e cotidianos não fornece em si, portanto, os critérios para o conhecimento ou para o currículo. Se seguirmos a análise de Engestrom, a importância da distinção feita por Vygotsky surge somente quando colocamos sua distinção na estrutura do movimento dialético da história e, a partir daí, desenvolvemos um conjunto de critérios metodológicos para gerar conceitos científicos. A dialética, como implica a citação de llyenkov, referese às "leis universais do pensamento" e aplica-se não apenas ao "pensamento científico e ao chamado pensamento cotidiano", mas a todos os campos do conhecimento.

Engestrom resume a abordagem dialética em uma citação do psicólogo russo Davydoff :

...a formação do conceito genuíno ascende primeiro dos fenômenos percebidos como concretos para a abstração substancial que expressa a contradição interior geneticamente original do sistema investigado. Ela então prossegue para a generalização concreta, deduzindo as várias manifestações particulares de sua base de desenvolvimento. (Davydoff apud Engestrom, 1991)

Os problemas dessa abordagem para os elaboradores de currículo é que: a) ela é metodológica e não lida com aspectos reais; b) ela supõe a aplicabilidade universal da lógica dialética, não apenas como uma exposição do movimento da história, mas como uma metodologia para a geração de novos conhecimentos em todos os campos e como uma teoria de aprendizado e ensino e, portanto, como base para o currículo.

Hedegaard refere-se à abordagem de Vygotsky como "um método de conhecimento teórico [que envolve] a associação de instâncias concretas a idéias genéricas... e a compreensão das generalidades como instâncias concretas" (Hedegaard, 1999, p.29). No entanto, nem de longe fica claro o que diferencia esse "método" ou de onde vêm as 'idéias genéricas'. No mesmo trabalho, Hedegaard afirma que

O significado dos conceitos... é formado dialeticamente por meio das relações dos conceitos uns com os outros. Por exemplo, no tema evolução, os conceitos de espécie e população definem um o outro (Hedegaard, 1999, p.29).

Aqui o método dialético parece perder completamente sua particularidade; ele meramente descreve o modo como os biólogos evolucionistas definem conceitos em seu campo, do mesmo modo como os químicos relacionam a estrutura atômica e a periodicidade dos elementos. Ficamos com um método genérico de- 
mais para ter qualquer aplicabilidade ou que envolve pressupostos que não necessariamente se aplicam a campos específicos. Quais são então os pontos fortes de uma interpretação dialética da abordagem de Vygotsky para a teoria do currículo? Primeiro, ela enfatiza a importância de uma abordagem histórica para o desenvolvimento do conhecimento. Segundo, tenta manter unidos três processos que estão inextricavelmente ligados na história da humanidade, mas são invariavelmente tratados em separado, tanto nos modelos de currículo quanto na pesquisa. Esses processos são: a) o movimento da história como a transformação das relações dos homens entre si e com a natureza, b) o crescimento e o desenvolvimento do conhecimento; e c) os processos de aprendizado e desenvolvimento. Terceiro, ela define o conhecimento, e portanto o currículo, em termos de propósitos, não de noções fixas de objetividade ou do conhecimento pelo conhecimento.

No entanto, como ilustrou o exemplo anterior de Hedegaard, uma abordagem dialética opera em um nível muito elevado de generalidade quando se trata de identificar opções específicas de currículo. Embora reivindique ser uma crítica das abstrações do ponto de vista do movimento real da história, ela é, de fato, outra abstração reivindicando ser o desenvolvimento da realidade histórica. Além disso, assim como supervaloriza o método, mesmo no sentido teórico, a abordagem dialética minimiza a importância de análises concretas. Desconheço qualquer exemplo de aplicação do método dialético, a não ser retrospectivamente, ou de aplicação que resulte na geração de novos conhecimentos em qualquer campo. É difícil vislumbrar que tipo de regras gerais poderiam existir para identificar conceitos historicamente produtivos, por exemplo, na química, literatura e história, que fossem além dos conceitos centrais que seriam identificados por especialistas em seus campos. As regras da dialética são, na prática, se não na teoria, formais, e não de uso real. Não existe "categoria de conhecimento" distinta no seio da dialética, portanto, o conhecimento tem de ser importado ou suposto.

Minha conclusão é que o valor de uma interpretação dialética da distinção feita por Vygotsky entre conceitos científicos e cotidianos está no fato de nos lembrar que categorias como a ciência não são determinadas e que os currículos não se restringem à escola. Na próxima seção, recorro à análise de Durkheim sobre o pragmatismo (Durkheim, 1983) para sugerir como uma abordagem do tipo proposto por Vygotsky pode ser fortalecida ao introduzir-se a idéia do conhecimento como uma categoria distintiva ao mesmo tempo em que preserva suas origens históricas. 


\section{CONHECIMENTO COMO CATEGORIA DISTINTIVA: ABORDAGEM DE DURKHEIM}

Na seção anterior, recorri ao trabalho de Engestrom para situar a distinção feita por Vygotsky entre os conceitos científicos e cotidianos no seio da estrutura da lógica dialética. No entanto, o método dialético supõe uma visão particular do desenvolvimento histórico, e esse conhecimento só pode ser entendido em termos de suas conseqüências, e não das explicações encontradas nas estruturas de entendimento compartilhadas por comunidades de especialistas. Esses pressupostos significam que, de fato, é negado um papel para o conhecimento como uma categoria distinta e, portanto, tal abordagem não consegue atingir suas pretensões de fornecer uma teoria produtiva do currículo. Não há elementos para supor que o desenvolvimento da história ou a geração de conhecimento em campos diferentes ou o processo de aquisição do conhecimento possam ser subordinados aos princípios do método dialético, exceto no sentido mais genérico e, portanto, não muito útil. Como resultado, abordagens que dependem de um método dialético não conseguem evitar a aceitação implícita de alguns conhecimentos como determinados e alguns conceitos como capazes de generalização. As conseqüências disso, como no caso de como as idéias de Vygotsky foram usadas nos países do bloco soviético na era stalinista, estão longe de ser insignificantes ${ }^{15}$.

Exemplos do conteúdo mais relevante do método dialético às vezes mencionados são a inter-relação dos conceitos e o princípio da contradição. No entanto, abstraídos do historicismo do marxismo, também não são distintivos; o primeiro é familiar a teóricos de sistemas e o último a algumas formas do funcionalismo proposto por Merton, de que a pesquisa sociológica deva centrar-se nas conseqüências não intencionais. A questão, portanto, é se ficamos com as abstrações aistóricas de Durkheim ou com um historicismo fora de lugar, que afirma conhecer o curso da história, como as únicas alternativas ao conservadorismo do princípio de insularidade ou ao relativismo do hibridismo. No restante desta seção, sugiro que o trabalho posterior de Durkheim sobre o pragmatismo de fato oferece uma base para tratar o

I5 O psicólogo soviético L.V. Zankov invocou a autoridade de Vygotsky no desenvolvimento dos seguintes princípios didáticos: a.) alto nível de dificuldade do assunto; b.) ritmo rápido de instrução; c.) papel destacado do conhecimento teórico; d.) trabalho escolar consciente dos alunos; e.) desenvolvimento sistemático e baseado em metas de cada aluno da classe. Peter Gavora (Universidade de Comenius, Bratislava) informou-me que a tentativa de introduzir esses princípios quase quebrou o ensino fundamental da Tchecoslováquia entre 1970 e 1980. 
conhecimento como uma categoria distinta (em outras palavras, que o conhecimento envolve proposições sobre a verdade que podem ter graus variados de autonomia de suas origens sociais ou contexto de aquisição). Em segundo lugar, procuro demonstrar que a abordagem de Durkheim da objetividade do conhecimento é mais complementar do que antagônica à interpretação dialética de Vygotsky.

Como demonstraram Rytina e Loomis ( 1970), embora o conteúdo do marxismo e do pragmatismo sejam bastante diferentes, a estrutura dialética das duas teorias, ambas com raízes hegelianas, é extraordinariamente similar. Ambas rejeitam o escolasticismo da filosofia acadêmica em nome da fusão da teoria com a prática. Ambas sustentam que a validade do conhecimento e a objetividade da verdade são questões práticas a serem julgadas em termos de propósitos e resultados humanos. $\bigcirc$ conhecimento é válido tanto para o marxismo quanto para o pragmatismo, desde que se destine ao aperfeiçoamento da humanidade (muito embora divirjam profundamente sobre o que esse aperfeiçoamento envolveria). Durkheim não deu muita atenção direta ao marxismo, pelo menos em seus escritos. No entanto, ele faz uma distinção bem nítida entre sua visão de que a religião tem origens sociais e a idéia marxista de que a religião não passa de "uma tradução, para uma outra língua, do alicerce material da sociedade" (Durkheim, 196 I, p.47I).

Para este autor, embora toda vida social "carregue a marca de seu alicerce material", a consciência coletiva é mais do que um epifenômeno - ela tem vida e objetividade próprias. Ele estava, no entanto, muito mais preocupado com o pragmatismo do que com o marxismo, por razões bem específicas ${ }^{16}$.

Durkheim elogiava o pragmatismo por sua "percepção elevada da realidade humana", em contraste com o idealismo difuso de outras teorias da época. Durkheim, como os pragmatistas, concordava que "tudo o que constitui a razão, seus princípios e categorias, foi feito no curso da história".

No entanto, ele preocupava-se com o fato de que, para o pragmatismo, a verdade e o conhecimento não tinham um caráter externo convincente; tinham apenas um valor utilitário e prático. A verdade e o conhecimento em qualquer sentido objetivo eram, se o pragmatismo estivesse certo, no máximo, instrumentos

I6 Embora Durkheim simpatizasse com o pragmatismo de James e Dewey como um tipo de filosofia sociológica, ele preocupava-se com seus vínculos com a filosofia idealista que estava sendo popularizada na França na época de Bergson. Durkheim argumentava que a idéia instrumental da verdade associada com o pragmatismo podia ser utilizada para minimizar a credibilidade da ciência, enfraquecendo sua reivindicação à objetividade. 
úteis para organizar a vida cotidiana. A visão de Durkheim era a de que a objetividade da verdade e do conhecimento (e da moralidade) é real, independentemente de ser ou não percebida como útil. Primeiro, a objetividade do conhecimento é necessária para orientar as pessoas em sua existência coletiva na sociedade. Esse é o conhecido argumento durkheimiano de que, nas condições da modernidade, valores compartilhados têm um papel integrador fundamental, pois a diferenciação social significa que a interdependência, e não a similaridade, constitui o modo característico pelo qual as pessoas se relacionam umas com as outras. Além disso, no entanto, Durkheim considerava que o conhecimento e a verdade têm como característica peculiar serem convincentes e que esse caráter obrigatório do conhecimento era a principal condição para a produção de novos conhecimentos - um discernimento freqüentemente ausente na sociologia contemporânea da ciência.

Durkheim argumentava que o pragmatismo causa o aniquilamento da verdade transformando-a em sensações, instintos e na consciência dos indivíduos; de modo similar, a dialética marxista vinculava a verdade à emancipação da classe trabalhadora na história e, na era soviética, às exigências das políticas do Partido Comunista. As duas teorias, para Durkheim, negligenciam o caráter obrigatório fundamental da verdade e do conhecimento - a primeira substituindo-o pelo benefício individual, a última, pelo poder político. Durkheim conclui, primeiro, que os argumentos para a objetividade do conhecimento são sociais e não filosóficos e, segundo, que o conhecimento se relaciona com as causas das coisas e não com as suas conseqüências. A causalidade para Durkheim, seja religiosa ou científica, tem uma base conceitual e, portanto, social.

Por que o argumento de Durkheim sobre o conhecimento é tão importante para o currículo? A resposta remonta a uma colocação anterior que fiz sobre as diferenças entre as visões de Durkheim e de Vygotsky quanto às origens sociais do conhecimento. Mostrei que Durkheim situava as origens do conhecimento teórico nas crenças religiosas compartilhadas de membros de sociedades primitivas e que, para ele, a importância da crença religiosa não era que ela solucionava os problemas práticos, mas sim que dava às pessoas um sentido - que não poderiam gerar a partir da experiência - de quem eram e para onde estavam indo. Também era, em sua concepção, a base paradigmática para todo o pensamento conceitual, inclusive a ciência. Vygotsky, ao contrário, situa a ciência e outras formas mais elevadas de pensamento na busca dos primeiros homens por alimento e abrigo. Para ele, a religião, por não ter contribuído para o desenvolvimento humano e, portanto, para a concretização do destino do homem, não era importante e esvaeceria. $\bigcirc$ conhecimento importante desenvolvido pelos primeiros homens foi o que adquiriram ao 
se apropriarem da natureza. Essa diferença subjaz à base social da realidade, separada do conhecimento como uma categoria distinta, e à separação fundamental do conhecimento teórico (originalmente a religião) e do senso comum, para Durkheim, assim como subjaz à sua integração igualmente fundamental, para Vygotsky. A ciência, como desenvolvimento e demonstração de conceitos inobserváveis e socialmente compartilhados, não era, para este último, uma atividade distinta; era parte integrante do modo pelo qual o homem se apropriava da natureza na história. Assim, na medida em que Vygotsky era um marxista, questões epistemológicas sobre o conhecimento como uma categoria separada, distinta da prática, não existiam; elas eram sempre resolvidas na prática, no curso da história. Segue-se que a distinção feita por ele entre os conceitos científicos e do senso comum era contingente, para ser superada na prática e por meio do aprendizado. Para Durkheim, a separação entre o conhecimento teórico e o senso comum não era contingente; era real. $\bigcirc$ desenvolvimento do conhecimento envolvia a substituição progressiva de um tipo de conhecimento sagrado ou teórico (religião) por outro (ciência), por conseguinte, a base social necessária da diferenciação do conhecimento.

A complementaridade dos dois teóricos pode ser expressa como se segue. A sociologia do conhecimento de Durkheim negligencia a apropriação técnica da natureza enfatizada por Vygotsky e não consegue explicar de modo adequado como os conceitos inobserváveis desenvolvidos pelas primeiras religiões tornaram-se os conceitos da ciência moderna, com o poder de transformar o mundo. Vygotsky, por outro lado, ao situar as origens do conhecimento nas atividades práticas do homem primitivo, não consegue explicar de modo adequado como essas atividades práticas foram transformadas pela teoria. Portanto, as duas abordagens podem ser vistas como complementares, mais do que meras críticas uma da outra. $\bigcirc$ currículo deve enfocar tanto a realidade social do conhecimento salientada por Durkheim quanto o processo histórico de transformar o conhecimento e o mundo, prioridade de Vygotsky. Em Durkheim existe um sentido que nos dá a base para um currículo, mas nenhuma pedagogia, ao passo que Vygotsky nos dá uma pedagogia, mas nenhum currículo.

\section{CONCLUSÕES}

No início deste artigo foi sugerido que havia uma tensão, subjacente ao futuro desenvolvimento do currículo, entre o princípio da insularidade e os argumentos cada vez mais aceitos em favor do hibridismo, bem como entre seus pressupostos antagônicos sobre a natureza do currículo e a relação deste com o conhecimento 
cotidiano. Em prosseguimento, examinei a teoria social do conhecimento de Durkheim e os argumentos que sua teoria oferece com vistas a salientar a especificidade do conhecimento teórico e o papel do currículo escolar, que é o de propiciar oportunidades para as pessoas adquirirem esse conhecimento. Os argumentos de Durkheim sugerem que devemos ser cautelosos quanto à falta de clareza das fronteiras entre as disciplinas e matérias e quanto ao enfraquecimento das pesquisas especializadas e das comunidades pedagógicas a elas associadas. Sugiro, no entanto, que uma análise durkheimiana, ao deixar de enfatizar o caráter histórico do conhecimento, pode conduzir a uma visão estreita e conservadora do conhecimento como algo determinado. Mais ainda, tal análise é incapaz de dar conta das mudanças sociais mais amplas que moldam o conhecimento e o currículo.

Para tratar dessas questões, voltei-me para o trabalho de Vygotsky e, em particular, para a distinção que ele faz entre conceitos científicos e cotidianos. Analisei algumas das semelhanças e diferenças significativas entre as idéias de Durkheim e Vygotsky e, ainda, como suas diferentes interpretações das origens sociais do pensamento nas sociedades primitivas, em parte, relacionam-se. De uma perspectiva marxista (e conseqüentemente de Vygotsky), conceitos científicos e cotidianos e suas inter-relações fazem parte das tentativas humanas de transformação do mundo ao longo da história. Para examinar criticamente os pontos fortes e fracos dessa abordagem, o artigo baseia-se nos escritos de Engestrom. Ao subordinar a lógica e o conhecimento à história, tentei demonstrar que isso não consegue explicar um aspecto característico de nossa era - o crescimento exponencial do conhecimento e sua capacidade de transformação do mundo. Embora o conhecimento seja sempre um produto das ações dos indivíduos na história, pelo menos a partir do século $\mathrm{XVII}$ (e em alguns casos até mesmo anteriormente), o conhecimento transcendeu os contextos nos quais se desenvolveu de forma que seria inconcebível em épocas anteriores.

O conhecimento, como a verdade e a moralidade, é inevitavelmente exterior ao aluno e àqueles que tentam criar um conhecimento novo. Daí a significância das fronteiras e classificações que distinguem o conhecimento do senso comum e que Durkheim enfatizava. Portanto, não existe alternativa, eu diria, para o que denominarei abordagem realista social ${ }^{17}$ do conhecimento e do currículo. Esse tipo de abordagem é social porque reconhece, como Marx, Durkheim e Vygotsky, o papel

17 Ao usar este termo não estou sugerindo nenhuma ligação com a tradição do realismo social na arte e no cinema. 
do agente humano na produção do conhecimento. $\bigcirc$ conhecimento nunca pode ser tomado como algo determinado, exceto em um sentido temporário, pois ele é sempre parte da história. Da mesma forma, a abordagem que proponho do conhecimento e do currículo é realista, porque reconhece as características do conhecimento independentes do contexto, e também que as poderosas interrupções de continuidade entre conhecimento e senso comum não são separações transientes a serem superadas progressivamente, mas sim reais condições que nos possibilitam obter conhecimento a respeito do mundo. $O$ conhecimento é construído social e historicamente, mas não pode ser subordinado aos processos de construção históricos e sociais; em outras palavras, nós produzimos conhecimento a partir do conhecimento. Ao mesmo tempo, essa realidade do conhecimento é, ela mesma, social em sua origem. Ao mesmo tempo em que o reconhecimento do caráter social do conhecimento e a negligência de sua realidade objetiva podem levar ao relativismo ou dogmatismo, um enfoque na sua realidade objetiva sem o reconhecimento de seu caráter social pode tornar-se pouco mais do que uma justificação do status quo. Um currículo do futuro precisa tratar o conhecimento como um elemento distinto e não redutível no processo histórico em que os indivíduos se esforçam para superar as circunstâncias nas quais se encontram. Retomando o ponto de partida deste artigo, essas circunstâncias referem-se à produção, reprodução e transposição das fronteiras entre disciplinas e entre o conhecimento de banco de escola e de local de trabalho. Essas fronteiras podem ser "prisões e estereótipos...(e)....pontos de tensão que condensam o passado e descortinam futuros possíveis" (Bernstein, 2000).

Entretanto, considerar essas tensões entre o legado do passado e as pressões do futuro como um processo histórico não é suficiente. Reconhecer que o conhecimento tem uma objetividade, e não é apenas um processo histórico, é importante por dois motivos. $\bigcirc$ primeiro consiste na exterioridade do conhecimento que Durkheim apontava e que é condição necessária para a criação e aquisição de novos conhecimentos. $\bigcirc$ segundo motivo da importância da objetividade do conhecimento está associado ao crescimento da ciência no decorrer dos séculos, a partir do lluminismo. Isso não exige que acreditemos - como Durkheim e Marx acreditavam - que estava surgindo um único método científico comum que gradualmente ampliaria seu escopo do mundo natural para o mundo social. Faz-nos reconhecer, no entanto, que regras, códigos e valores associados com tradições de diferentes especialidades, que propalam afirmações largamente aceitas a respeito do conhecimento e de como ele é gerado e adquirido, desenvolveram-se. Um currículo que se arvora ser "do futuro" não pode se eximir de tratar o conhecimen- 
to que surgiu de tais tradições e comunidades de especialistas como uma categoria em si mesma e de esforçar-se para assegurar aos alunos o acesso às regras para sua aquisição e produção.

A idéia da verdade como algo exterior ao indivíduo, embora social (e, por conseqüência, essencialmente humano) era condição, afirmava Durkheim, tanto para a produção do conhecimento como para nossa orientação de que somos membros de uma sociedade. Para ele, assim como os ideais da moral constituem as regras de conduta, da mesma forma, a verdade constitui a regra do pensamento e, eu acrescentaria, o conhecimento deve constituir a regra do currículo.

Uma abordagem que se atenha demasiadamente a Durkheim traz consigo o risco de facilmente tornar-se estática. Na ciência, assim como em todos os outros campos, o conhecimento sofre mudanças. A tradição marxista da dialética, à qual Vygotsky estava associado, rejeitava essa visão estática do conhecimento, colocando sua confiança não no conhecimento, mas na história, "que estava a favor deles". A partir do lluminismo, pelo menos, é o conhecimento e não a história que, apesar de todas as suas fraquezas, e com mais sucesso em alguns campos do que em outros, tem sido a melhor garantia da verdade. Foram estabelecidos métodos, teorias e debates nas disciplinas e, em sua maioria (embora nem todas), as descobertas interdisciplinares ou multidisciplinares tiveram origem no interior das disciplinas e não externamente a elas (embora algumas vezes resultantes de tentativas de rompimento com essas mesmas disciplinas). A maneira mais adequada de considerar-se o hibridismo é como uma tentativa de contestar a autoridade disciplinar ou de acelerar os "rompimentos". O método dialético, se concebido de uma forma mais ampla, é uma tentativa de dar dimensão histórica, transformadora e intencional ao hibridismo. A dialética era defendida, pelo menos entre os marxistas, até duas décadas atrás. Embora com aspirações e pretensões convincentes, seus métodos eram inadequados e os resultados, incipientes. $\bigcirc$ hibridismo surgiu em décadas recentes como resposta às pressões econômicas, para que fosse superada a separação entre teoria e prática. Todavia, da mesma forma que a dialética, não foi capaz de fornecer as condições para a geração de novos conhecimentos ou conceitos. Quando aplicado ao currículo, ele faz cair por terra as fronteiras e limita as possibilidades de aquisição de novos conhecimentos.

Novos conhecimentos e novos currículos são gerados quando pesquisadores ou alunos adquirem e desenvolvem o conhecimento e conceitos existentes de disciplinas e campos específicos a fim de entender ou transformar o mundo. A insularidade e o conceito do sagrado de Durkheim são maneiras sugestivas de descrever-se a estrutura do conhecimento e sua base social. $\bigcirc$ hibridismo realça o 
aspecto historicamente contingente dessas estruturas sem oferecer-nos uma idéia muito clara de para onde elas vão, ou da sua maior ou menor dependência de fatores históricos. A distinção, feita por Vygotsky, entre conceitos científicos e cotidianos preserva a distinção entre teoria e senso comum, que se encontra também em Durkheim, e sugere que a relação entre os dois precisa ser situada historicamente e compreendida em relação a uma noção mais abrangente dos objetivos humanos. Sua importância para a teoria do currículo não se encontra, da forma como vejo, em seus conceitos específicos. Os conceitos são sugestivos, porém, ou muito gerais para esclarecer de que forma poderiam ser desenvolvidos ou, se usados como na era soviética, sem nenhuma crítica, passíveis de mau uso. Sua importância repousa em sua tentativa heróica de manter a união entre os processos de aprendizagem e a geração de novos conhecimentos que a especialização exagerada no currículo e nas comunidades de pesquisa separaram. Quais os teóricos da globalização que são também teóricos da pedagogia e do currículo? Estou certo de que Vygotsky o seria, caso ainda vivesse.

\section{REFERÊNCIAS BIBLIOGRÁFICAS}

BACKHURST, D. Social constructionism, meaning and mind. Institute of Education, [paper pretender] 2002.

BERNSTEIN, B. Class, codes and control. v. I. London: Routledge and Kegan Paul, I97I . Pedagogy, symbolic controland identity, Lanham, USA: Rowman and Littlefield, 2000.

COLLINS, R. The Sociology of philosophies. Cambridge, Mass: Belknap Press, 1998.

DANIELS.H. Vygotsky and pedagogy. London: Routledge Falmer, 2000.

DURKHEIM, E. The Division of labour in society. New York: Free Press, 1964. The Elementary forms of religious life. New York: Collier Books, 1961.

Pragmatism and sociology.Cambridge, UK: Cambridge University Press, 1983.

ENGESTROM, Y. Learning by expanding. 1991. Disponível em: < http://I chc.ucsd.edu/MCA Paper/Engestrom/expanding/toc.htm.>

GELLNER, E. Reason and culture. Oxford, UK: Blackwell, 1992.

GIBBONS, M. L. etal. The New production of knowledge. London: Sage, 1994. 
HEDEGAARD, M. The Influence of societal knowledge traditions on children's thinking and development. In: HEDEGAARD, M.; LOMPSCHER, J. (eds.). Learning activity and development. Aarrhus, Denmark: Aarrhus University Press, 1999.

HORTON, R. Levy-Bruhl, Durkheim and the scientific revolution In: HORTON, R.; FINNEGAN, R. (eds.). Modes of thought. London: Faber, 1974.

LURIA, A. R.; VYGOTSKY. L. S. Ape, primitive man and child. Hemel Hempstead, UK: Harvester Wheatsheaf, 1992.

MOORE, R.; YOUNG, M. Knowledge and the curriculum in the sociology of education: towards a re-conceptualisation. British Journal of Sociology of Education, v. 22, n. 4, p.445, 2001 .

MULLER, J. Reclaiming knowledge. London: Routledge Famer, 2000.

REICH, R. The Work of nations. London: Simon and Schuster, I99I.

RYTINA, J. H.; LOOMIS, C.P. Marxist dialectic: power as knowledge. American Sociological Review, 1970.

VYGOTSKY, L.S. The Collected works of L.S Vygotsky. New York and London: Plenum Press, 1998.

Thought and language. Cambridge, Mass: MIT Press, 1962.

WARD, S. Reconfiguring truth. Lanham, USA: Rowman and Littlefield, 1996.

YOUNG, M. F. D. The Curriculum of the future. London: Falmer Press, 1998.

Recebido em: agosto 2002

Aprovado para publicação em: setembro 2002 